\title{
Como o acesso à educação desmonta o mito da democracia racial*
}

Nara Torrecilha Ferreira a

\section{Resumo}

Este ensaio pretende mostrar como a Educação, particularmente o acesso ao Ensino Superior, é um excelente indicador para desmontar o mito da democracia racial constituído no imaginário brasileiro. Assim, o texto divide-se em três partes e conclusão. Primeiro, são apresentados e debatidos os argumentos relativos à ideia de democracia racial. Em seguida, são analisadas as políticas de ação afirmativa. Depois, são analisadas as possibilidades de acesso dos negros ao Ensino Superior. $\mathrm{Na}$ conclusão, o artigo discute a importância de políticas para o combate às desigualdades raciais, realçando uma agenda de pesquisa que possibilitaria entender, em que medida as políticas afirmativas seriam capazes de mudar o quadro racial brasileiro.

Palavras-chave: Educação superior. Acesso. Políticas afirmativas. Desigualdade.

\section{0 argumento da democracia racial e os dados educacionais}

No Brasil, vários grupos são historicamente marginalizados e seus membros excluídos do exercício da cidadania. A democracia racial brasileira, alardeada por anos, assevera a ideia de que as relações de raça seriam harmoniosas. Muitos defendem que o critério racial jamais foi relevante para definir as chances de qualquer pessoa no país. No entanto, a vergonha do brasileiro de demonstrar o próprio preconceito não significa que a discriminação racial não exista, e ainda dificulta o combate ao racismo, por inibir discussões abertas sobre o tema. Guarnieri e Melo-Silva (2007) defendem que, no Brasil, o segregacionismo, embora não declarado, é cultuado socialmente de maneira silenciosa e, por isso, a discriminação racial no Brasil encontra meios informais de propagação e é dificilmente assumida.

\footnotetext{
* Pesquisa realizada sob orientação do Prof. Dr. Fernando Luiz Abrucio (FGV-SP).

a Fundação Getúlio Vargas, São Paulo, SP, Brasil.
} 
Assim, a imagem que o país sempre buscou difundir, de nação mestiça, que superou o problema da discriminação racial e constituiu um modelo de integração para o mundo, hoje esbarra na decadência do mito da democracia racial. Aqui, a mestiçagem foi utilizada como escudo para evitar o reconhecimento da importância da população negra na história e na vida cultural brasileira, bem como para exaltar um dos grandes mitos da sociedade brasileira: o de que constituímos uma democracia racial. A natureza do debate sobre a mestiçagem no Brasil, apesar de conviver permanentemente com ambiguidades e contradições, sofreu poucas mudanças no decorrer dos últimos 100 anos (ARAÚJO, 2008). Dessa maneira, o Brasil não reconhece verdadeiramente o nosso maior patrimônio cultural, a nossa multirracialidade.

O caráter mestiço do povo brasileiro e as suas consequências para o destino da nação transformaram-se na questão fundamental da nacionalidade no país no final do século XIX (OLIVEIRA FILHO, 2009). A elite intelectual brasileira da década de 1930 passou a defender a ideia de que um projeto de desenvolvimento viável para o Brasil só seria bem-sucedido pela aceitação do caráter mestiço da sociedade, apresentando-a como um cruzamento de identidades entre brancos, negros e índios, convivendo de forma harmoniosa (ALVES; GALEÃO-SILVA, 2004). De acordo com Alberti e Pereira (2007), a partir da década de 1970, as principais formas de atuação do movimento negro passaram a se concentrar na denúncia do mito da democracia racial. Para Pereira (2007), influenciados pelas lutas envolvendo as populações negras na África e nos Estados Unidos, em meados do século XX, a preocupação com o estabelecimento de um estatuto legal levou à introdução, na Constituição de 1988, de artigos voltados para direitos raciais e, mais recentemente, à aprovação do Estatuto da Igualdade Racial. Por outro lado, Alberti e Pereira (2007) estão corretos ao afirmar que embora esses passos sejam importantes, não significavam, e ainda não significam, efetividade de políticas públicas voltadas para a população negra.

Nesse sentido, Alves e Galeão-Silva (2004) destacam a dificuldade histórica de identificar alguns grupos discriminados, tendo em vista que o mito da democracia racial brasileira dificulta o reconhecimento da discriminação e, por consequência, a identificação dos negros a serem incluídos em políticas de combate ao racismo. Grande parte de nossa intelectualidade continua acreditando que o problema da desigualdade no Brasil é apenas decorrente do fosso entre classes sociais, e não do nosso sistema de castas raciais (ARAÚJO, 2008). Nesse sentido, Pinto (2005) destaca que o debate sobre a implementação das cotas foi marcado pela polarização ideológica, sendo utilizado o argumento de fluidez das classificações raciais no Brasil como representante de uma visão de mundo "branca" e "negadora da existência do racismo", e de dados estatísticos sobre as desigualdades econômico-sociais entre 
brancos e negros como a "prova" da existência de uma sociedade racialmente bipolar com linhas de clivagem racial nítidas entre brancos e negros.

Essa alegada diluição é desmantelada do ponto de vista do acesso a direitos sociais e econômicos, em que fica evidente a diferença das cores predominantes em cada classe social. Assim, a miscigenação, que é apresentada como uma prova da inexistência de racismo no Brasil, e os outros temas que constituem o que se poderia chamar de discurso da democracia racial, têm sido usados com o objetivo de ocultar o caráter opressivo das relações raciais no país e impedir a adoção de medidas estatais que diminuam a desigualdade entre negros e brancos (OLIVEIRA FILHO, 2009).

A desigualdade social, decorrente da discriminação racial, perpassa os diversos setores da sociedade. Contudo, a restrição do acesso à educação em todos os seus níveis é, especialmente, perversa tendo em vista que o acesso ao ensino formal e de qualidade é o principal meio de emancipação dos cidadãos. Assim, a impossibilidade de formação educacional adequada compromete todo o futuro de uma geração. No Brasil, a educação é apresentada como integrante da categoria dos direitos sociais previstos no art. 6. ${ }^{\circ}$ da Constituição Federal (SENADO FEDERAL, 1988). Cabe ressaltar que os direitos sociais estão inseridos dentre os Direitos e Garantias Fundamentais. De acordo com Baltazar (2007), a educação, como um direito social fundamental, aponta, tanto no sentido da obrigatoriedade de sua oferta pelo Estado, quanto no de gestão democrática pela sociedade. Contudo, o art. 208 da Carta determina os limites dessa obrigação, definindo como impositivo ao Poder Público o dever de garantir a educação fundamental e gratuita, a progressiva universalização do Ensino Médio e, quanto ao Ensino Superior, tão somente o acesso aos níveis mais elevados de ensino. Cabe destacar que no contexto de redemocratização da sociedade brasileira dos anos de 1980, a articulação entre educação e democracia foi reelaborada, apontando a educação como um canal possível de reconstrução de participação política, construção de uma esfera pública e alcance de um Estado de direito democrático social (PERONI; OLIVEIRA; FERNANDES, 2009). Apesar dos problemas de qualidade da educação básica, é no Ensino Superior que o acesso à educação fica ainda mais restrito às camadas mais privilegiadas da sociedade.

A população brasileira é formada, predominantemente, por brancos, pretos e pardos. O Gráfico 1 apresenta dados da PNAD 2015 (IBGE, 2016) e mostra que a população negra totaliza $54 \%$ da população brasileira. Cabe observar que essa definição da constituição da população negra, englobando pretos e pardos, é adotada pelo Estado Brasileiro. Este é o público a quem destinam-se as políticas afirmativas raciais do Ensino Superior no Brasil. 


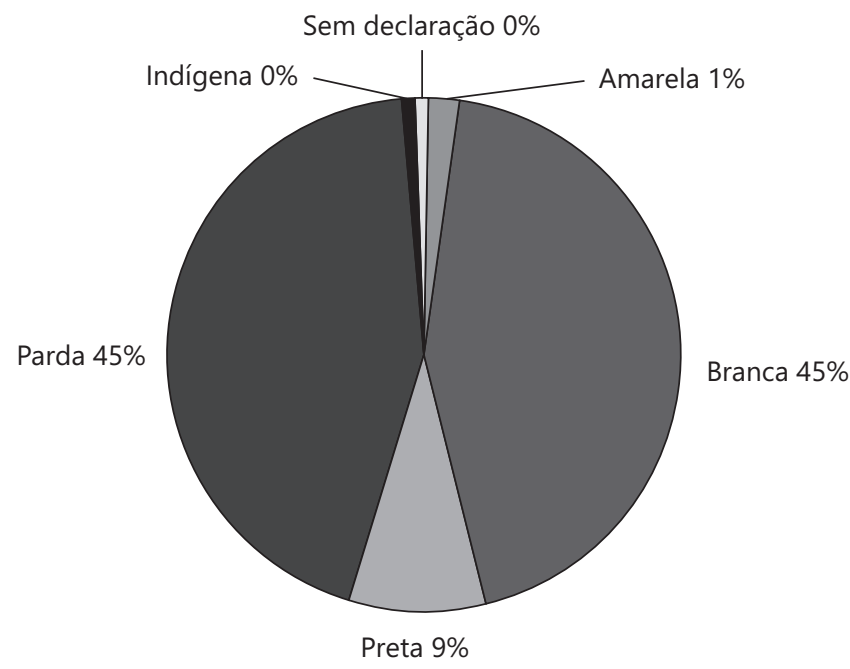

* Inclusive a população sem declaração de cor ou raça.

Fonte: Pesquisa Nacional por Amostra de Domicílios (PNAD) 2015 (IBGE, 2016).

Gráfico 1. Distribuição percentual da população, por cor/raça - 2015*.

O Gráfico 2 exibe dados da Pesquisa das Características Étnico-raciais da População (PCERP) 2008 (IBGE, 2011) em que 64\% das pessoas afirmaram que a cor ou raça influenciam a vida das pessoas.

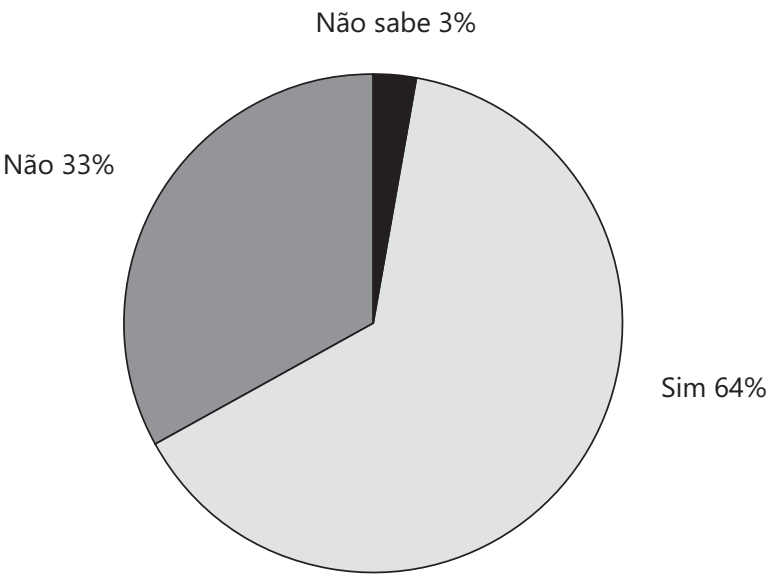

* Exclusive sem declaração.

Fonte: Pesquisa das Características Étnico-raciais da População 2008 (IBGE, 2011).

Gráfico 2. Pessoas de 15 anos ou mais de idade, total e distribuição percentual por influência da cor ou raça na vida das pessoas - 2008*. 
O Gráfico 3 apresenta a diferença na Taxa de Escolarização Líquida dos jovens brancos e negros (IPEA, 2015). Na medida em que os níveis de ensino sobem, as diferenças entre brancos e negros aumenta. Assim, enquanto no Ensino Fundamental a diferença é praticamente inexistente, a diferença sobe para 21,8\% no Ensino Médio e para 52,6\% no Ensino Superior.

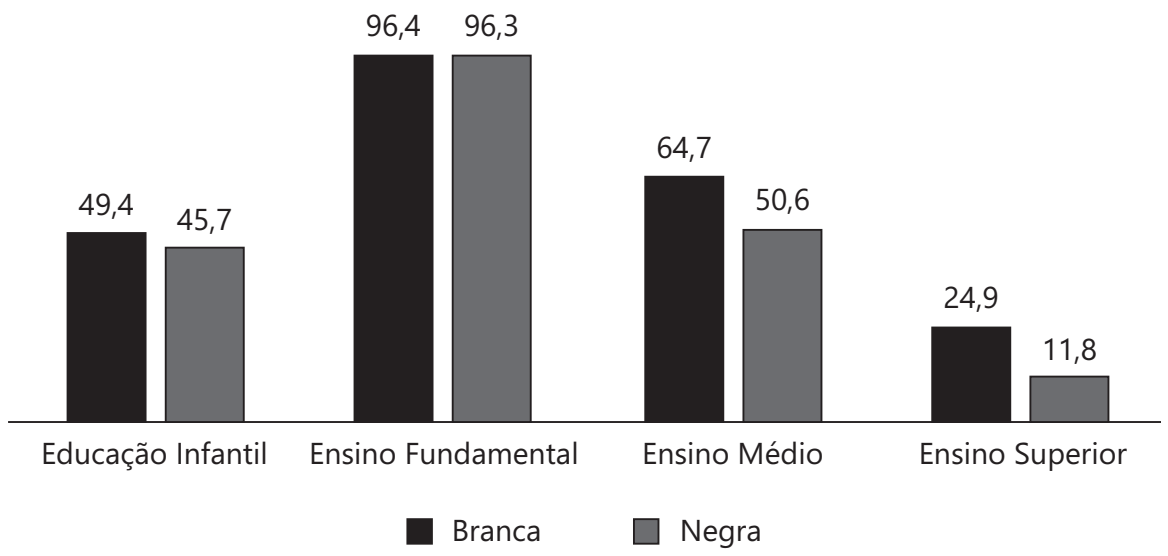

\begin{abstract}
* Foram considerados adequados ao Ensino Superior os indivíduos que frequentam graduação, mestrado ou doutorado. A taxa de escolarização líquida fornece a proporção da população matriculada no nível de ensino considerado adequado conforme a faixa etária.

Fonte: Retrato das desigualdades de gênero e raça - 1995 a 2014 (IPEA, 2015).
\end{abstract}

Gráfico 3. Taxa de escolarização líquida, segundo cor/raça e nível de ensino - 2014*.

Dado importante para o contexto de implementação das ações afirmativas é a discrepância na distribuição dos estudantes de 18 a 24 anos, por cor ou raça e nível de ensino. Na Tabela, os dados PNAD (IBGE, 2015) mostram que os jovens de cor branca são os menos defasados em relação ao nível de ensino, ou seja, são os que apresentam menor distorção entre a idade adequada e o nível que frequentam.

As desigualdades raciais observadas na educação são reflexos das desigualdades observadas na sociedade. Assim, o Gráfico 4 mostra que a taxa de trabalho infantil sempre foi maior entre a população negra, mesmo tendo caído de 2001 a 2014 (IPEA, 2015). 
Tabela. Estudantes de 18 a 24 anos de idade, total e respectiva distribuição percentual, por nível de ensino frequentado e cor ou raça, segundo as grandes regiões do Brasil - 2013.

\begin{tabular}{lccccc}
\hline Grandes Regiões & $\begin{array}{c}\text { Total } \\
(\mathbf{1 . 0 0 0} \text { pessoas) }\end{array}$ & Fundamental & Médio & Superior ${ }^{\mathbf{1}}$ & Outros $^{\mathbf{2}}$ \\
\hline Branca & & & & & \\
Brasil & 3.388 & 2,9 & 22,4 & 69,5 & 5,2 \\
Norte & 176 & 4,1 & 34,3 & 52,2 & 9,4 \\
Nordeste & 605 & 6,1 & 30,1 & 58,1 & 5,6 \\
Sudeste & 1.542 & 1,9 & 20,3 & 73,1 & 4,8 \\
Sul & 795 & 2,3 & 19,4 & 73,1 & 5,2 \\
Centro-Oeste & 271 & 2,0 & 18,5 & 75,5 & 4,0 \\
Negra & & & & & \\
Brasil & 3.389 & 8,8 & 43,4 & 40,7 & 7,1 \\
Norte & 510 & 11,7 & 46,1 & 34,0 & 8,2 \\
Nordeste & 1.350 & 12,9 & 46,7 & 33,7 & 6,6 \\
Sudeste & 1.051 & 4,4 & 41,6 & 47,3 & 6,7 \\
Sul & 161 & 4,7 & 37,6 & 45,5 & 12,2 \\
Centro-Oeste & 318 & 3,0 & 33,8 & 57,2 & 6,0 \\
\hline
\end{tabular}

${ }^{1}$ Inclui mestrado e doutorado.

${ }^{2}$ Pré-vestibular, supletivo e alfabetização de adultos.

Fonte: Pesquisa Nacional por Amostra de Domicílios (PNAD) 2013 (IBGE, 2015).

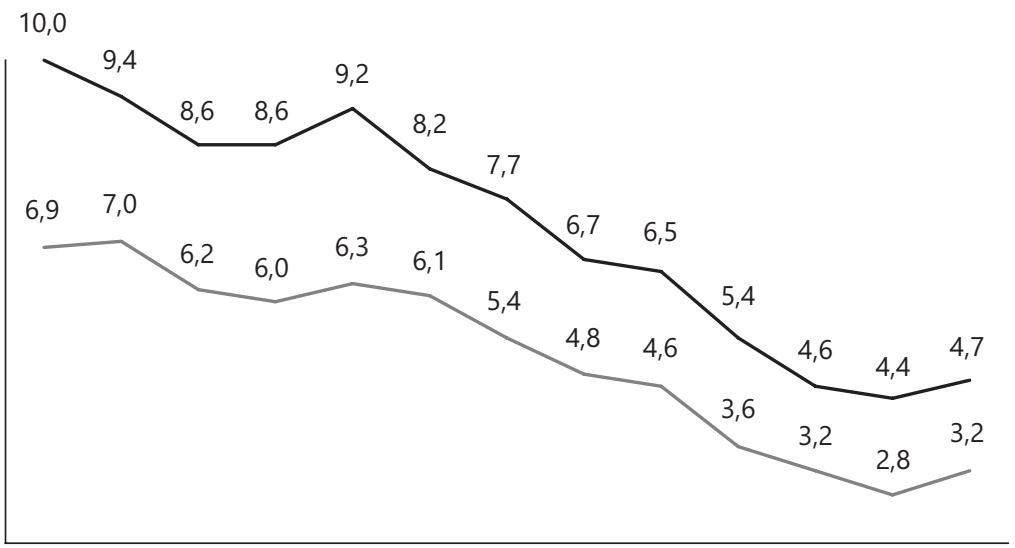

20012002200320042005200620072008200920102011201220132014

Branca

* A PNAD não foi realizada no ano de 2010. Em 2004 a PNAD passa a contemplar a população rural de Rondônia, Acre, Amazonas, Roraima, Pará e Amapá.

Fonte: Retrato das desigualdades de gênero e raça 1995 a 2014 (IPEA, 2015).

Gráfico 4. Taxa de trabalho infantil da população com idade entre 5 e 15 anos, por sexo, segundo cor/raça e localização do domićlio - Brasil e Regiões, 2001 a 2014*. 
Também diretamente relacionado com os dados mencionados, o Gráfico 5 apresenta a distribuição dos domicílios em assentamentos subnormais (IPEA, 2015). Observa-se que não só a população negra é maioria nesse tipo de assentamento, como a diferença vem aumentando, sendo que a participação da população branca vem caindo e a da população negra vem aumentando.

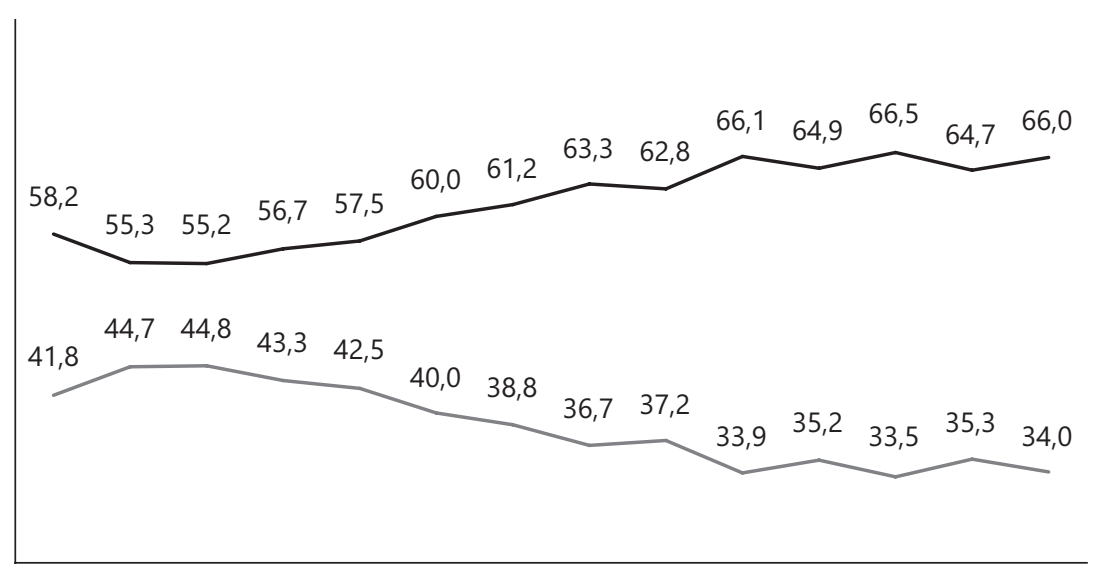

199519961997199819992000200120022003200420052006200720082009

- Branca

Negra

* Em 2004 a PNAD passa a contemplar a população rural de Rondônia, Acre, Amazonas, Roraima, Pará e Amapá. Assentamento subnormal: conjunto (favelas e assemelhados) constituído por unidades habitacionais (barracos, casas etc.), ocupando, ou tendo ocupado até período recente, terreno de propriedade alheia (pública ou particular), dispostas, em geral, de forma desordenada e densa, e carentes, em sua maioria, de serviços públicos essenciais.

Fonte: Retrato das desigualdades de gênero e raça 1995 a 2014 (IPEA, 2015).

Gráfico 5. Distribuição percentual dos domicílios particulares permanentes urbanos em assentamentos Subnormais, segundo cor/raça do/a chefe do domicílio - 1995 a 2009*.

A desigualdade entre brancos e negros também é percebida nos dados da previdência, conforme demonstra o Gráfico 6 (IPEA, 2015). Enquanto 63,4\% da população negra possui esse tipo de cobertura, esse percentual chega a $72,3 \%$ para a população branca. 


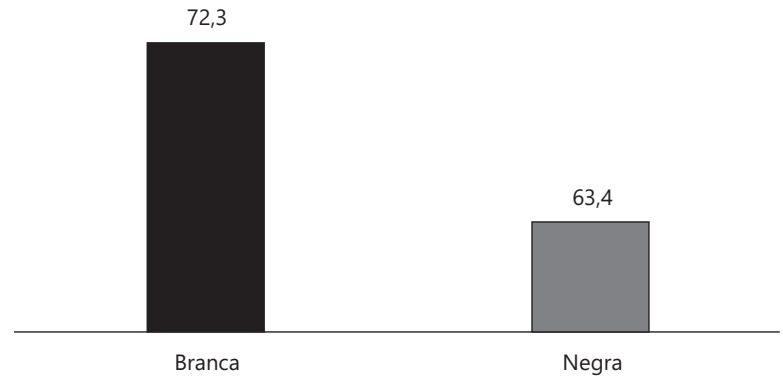

* São considerados cobertos diretamente pela previdência pública aqueles que contribuem diretamente, os funcionários públicos, militares e empregados com carteira de trabalho assinada em qualquer trabalho na semana de referência e os segurados especiais da previdência rural. São considerados cobertos indiretamente pela previdência pública os cônjuges e filhos até 21 anos de idade daqueles que são cobertos diretamente. Fonte: Retrato das desigualdades de gênero e raça 1995 a 2014 (IPEA, 2015).

Gráfico 6. Cobertura direta e indireta da previdência pública na população em idade ativa, segundo cor/raça $-2014^{*}$.

Esses dados sobre saúde e previdência são consequência direta do mercado de trabalho. Nesse sentido, o Gráfico 7 mostra que a população branca é maioria nas posições de ocupação mais estáveis e mais protegidas pela legislação trabalhista (funcionário público/militar, empregado com carteira assinada e empregador), enquanto a população negra prevalece nas posições de ocupação mais frágeis (empregado sem carteira assinada, conta própria e empregado doméstico).

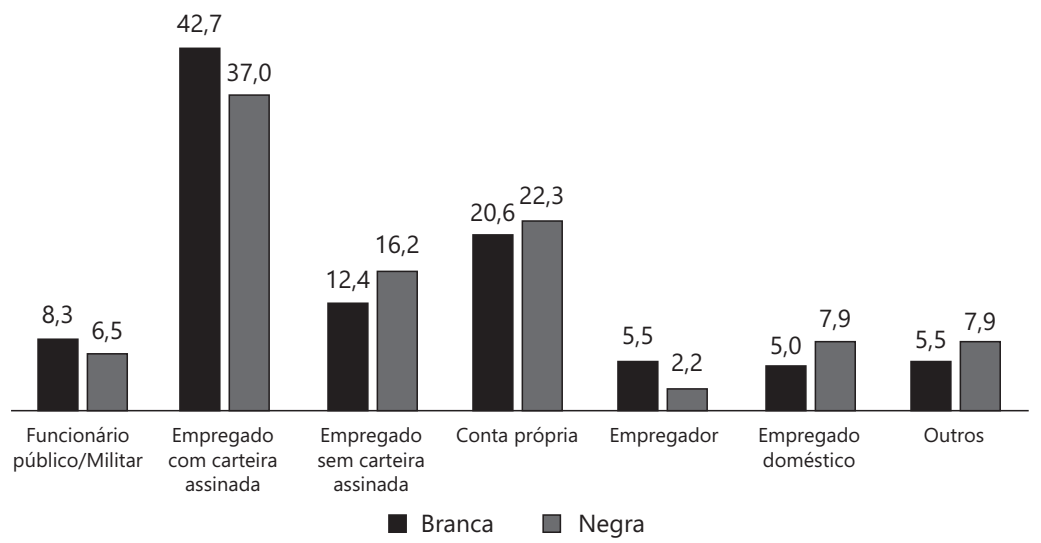

* Outros: trabalhadores na produção para o próprio consumo, trabalhadores na construção para o próprio uso e trabalhadores não remunerados.

Fonte: Retrato das desigualdades de gênero e raça 1995 a 2014 (IPEA, 2015).

Gráfico 7. Distribuição percentual da população ocupada com 16 anos ou mais de idade, por cor/raça e posição na ocupação - 2014*. 
A diferença de rendimento mensal domiciliar entre brancos e negros também é enorme, conforme Gráfico 8 (IPEA, 2015). Assim, o rendimento mensal domiciliar per capita médio da população negra era menos da metade do rendimento da população branca em 1995 e, em 2014, chegou apenas a pouco mais da metade.

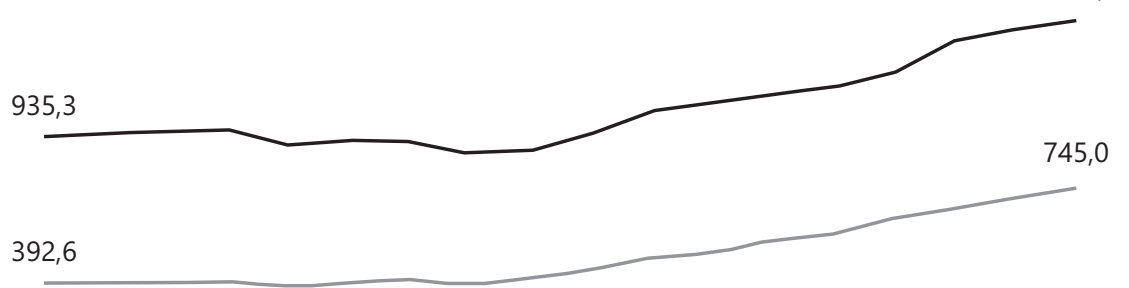

199519961997199819992001200220032004200520062007200820092011201220132014

_ Branca Negra

* A PNAD não foi realizada nos anos de 2000 e 2010. Em 2004 a PNAD passa a contemplar a população rural de Rondônia, Acre, Amazonas, Roraima, Pará e Amapá. Rendimento mensal domiciliar per capita deflacionado com base no INPC, período de referência set./2014.

Fonte: Retrato das desigualdades de gênero e raça 1995 a 2014 (IPEA, 2015).

Gráfico 8. Rendimento mensal domiciliar per capita médio, segundo cor/raça - 1995 a $2014^{*}$.

O Gráfico 9 mostra que o percentual de pessoas extremamente pobres, pobres e vulneráveis vem caindo em todos os grupos raciais e em quase todas as regiões do país, com exceção das regiões Norte e Nordeste, que apresentaram aumento no percentual de vulneráveis (IPEA, 2015). No entanto, esses grupos ainda concentram mais negros. Assim, enquanto a população negra é maioria entre os extremamente pobres, pobres e vulneráveis, a população branca é maioria entre os não pobres.

Como bem apontam Santos et al. (2008), o Brasil é um país formado por diferentes povos e a interação social entre eles foi desigual desde o início da colonização portuguesa, o que gerou grandes desigualdades pautadas por diferenças de classe social, de grupo racial e de sexo e gênero. De acordo com Guimarães (1995), é pela restrição fatual da cidadania e por meio da imposição de distâncias sociais 


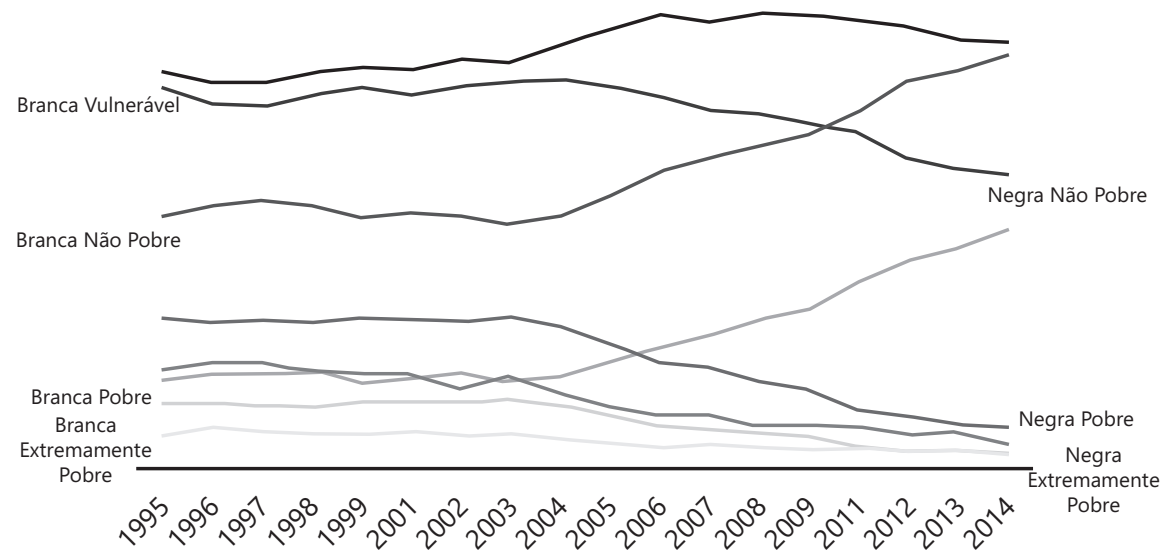

* A PNAD não foi realizada nos anos de 2000 e 2010. Em 2004 a PNAD passa a contemplar a população rural de Rondônia, Acre, Amazonas, Roraima, Pará e Amapá. Situação de pobreza calculada com base no rendimento mensal domiciliar per capita deflacionado pelo INPC, período de referências setembro/2014, Extremamente pobres - renda domiciliar per capita de até $\mathrm{R} \$ 77,87$; Pobres - renda domiciliar per capita maior ou igual a $R \$ 77,87$ e menor que $R \$ 155,74$; Vulneráveis - renda domiciliar per capita maior ou igual a $R \$ 155,74$ e menor que $R \$ 724$; Não pobres - renda domiciliar per capita maior ou igual a R\$724 (um salário mínimo de 2014). Fonte: Retrato das desigualdades de gênero e raça 1995 a 2014 (IPEA, 2015).

Gráfico 9. Distribuição percentual da população por cor/raça, segundo situação de pobreza definida com base no Programa Brasil sem Miséria, 1995 a 2014*.

criadas por diferenças enormes de renda, de educação e pelas desigualdades sociais que separam brancos de negros, ricos de pobres, nordestinos de sulistas, que o racismo se perpetua. Uma das principais questões no âmbito das políticas sociais é a diferenciação entre as políticas meramente compensatórias e as políticas de efetiva distribuição de renda. Num país como o Brasil, de extrema desigualdade social, a política social tem o papel não só de redistribuir a renda, mas também de redemocratização da estrutura ocupacional, constituindo-se num verdadeiro sistema de enfrentamento da questão social.

\section{Políticas afirmativas}

No Brasil, a alta concentração da renda, aliada à mão de obra pouco qualificada e ao trabalho informal, entre outros fatores, produziu um ciclo vicioso de exclusão social. A fim de buscar a minimização desse processo, a Constituição de 1988 introduziu avanços nas garantias sociais, com o estabelecimento de princípios e regras detalhadas. A Constituição (SENADO FEDERAL, 1988), no seu art. $3^{\circ}$, indica como objetivos fundamentais da República Federativa do Brasil construir uma sociedade livre, justa e solidária; garantir o desenvolvimento nacional; 
erradicar a pobreza e a marginalização e reduzir as desigualdades sociais e regionais; promover o bem de todos, sem preconceitos de origem, raça, sexo, cor, idade e quaisquer outras formas de discriminação.

Alves e Galeão-Silva (2004) afirmam que nos Estados Unidos as medidas em prol do acesso igualitário ao trabalho ganharam espaço na agenda pública nos anos 1960, em resposta à luta pelos direitos civis. Segundo eles, os governos Kennedy e Johnson introduziram leis que proibiam as diversas agências governamentais de discriminarem seus candidatos a emprego com base em cor, religião e nacionalidade, estimulando-as para que usassem de ação afirmativa na contratação de seus empregados. Conforme os autores, outros países têm implementado medidas contra a discriminação étnica e de gênero. De acordo com eles, na União Europeia, tais leis tratam de questões relativas ao multiculturalismo resultante dos fluxos migratórios recentes, e na África do Sul, objetivam desmontar formas discriminatórias herdadas do regime de apartheid.

Os casos do Brasil e dos Estados Unidos têm como ponto de partida comum a presença de um forte processo de dominação da população negra durante o período colonial. Ainda assim, em relação à raça, os modelos adotados pelos dois países foram fundamentalmente diferentes tanto no que diz respeito à relação entre o estatal e o privado, quanto no que diz respeito à regulação legal (AVRITZER; GOMES, 2013). Nesse sentido, Alberti e Pereira (2005) destacam o fato de as Constituições brasileiras elaboradas a partir da abolição da escravidão nunca terem diferenciado os cidadãos por raça ou cor, ao contrário do que acontecia nos EUA e na África do Sul. Nesses dois países, foram implantadas instituições de Ensino Superior exclusivas para negros, justamente em razão da segregação, enquanto no Brasil, esse grupo, simplesmente, permaneceu excluído do acesso ao Ensino Superior. Apesar dessas características, os países optaram pela implantação de políticas afirmativas, cada qual com o seu desenho, mas todas com o mesmo objetivo, de diminuir a discriminação racial e aumentar a inclusão de todos os segmentos raciais da população.

Bayma (2012) define ações afirmativas como iniciativas para promover a igualdade, reduzindo as injustiças sociais. De acordo com a autora, são práticas que consideram as desigualdades reais e, assim, podem ser instrumento hábil e efetivo para se promover o aumento de oportunidades de inclusão social. Já Bernardino (2002) define ações afirmativas como políticas públicas que pretendem corrigir desigualdades socioeconômicas procedentes de discriminação, atual ou histórica, sofrida por algum grupo de pessoas. Assim, as políticas de ação afirmativa buscam, por meio de um tratamento temporariamente diferenciado, promover a 
equidade entre os grupos que compõem a sociedade. Para Guarnieri e Melo-Silva (2007), as ações afirmativas podem ser compreendidas como medidas de caráter social que visam à democratização do acesso a meios fundamentais por parte da população em geral, com o objetivo principal de promover condições para que todos na sociedade possam competir igualmente pela conquista de tais meios. Por outro lado, Daflon, Feres Júnior e Campos (2013) afirmam que a ação afirmativa se diferencia das políticas antidiscriminatórias ,puramente punitivas, por atuar em favor de coletividades discriminadas e indivíduos que potencialmente são discriminados, podendo ser entendida tanto como uma prevenção à discriminação quanto como uma reparação de seus efeitos, enquanto políticas antidiscriminatórias puramente punitivas só se preocupam em coibir comportamentos e práticas que promovam discriminação, sem contudo cuidar da elevação das condições de vida de grupos e indivíduos discriminados.

Pinto (2005) destaca que a formalização de identidades sociais como sujeitos de direito reconhecidos pelo Estado tem efeitos profundos na dinâmica social, permitindo que aqueles que as reivindiquem tenham um acesso diferenciado a recursos, bens e serviços. Gomes e Moraes (2009) argumentam que o ingresso crescente de parcelas da população, incorporando diferenças sociais, econômicas, culturais, etnicorraciais e regionais ao sistema e às instituições de educação superior, tende a alterar a natureza e função desse nível de ensino, trazendo questões sobre a política de igualdade e equidade de oportunidades educativas, antes vistas como questões secundárias, e pressionando governos a formularem políticas afirmativas.

Diante dessa realidade social estruturada pelo mito da democracia racial e pelo ideal de branqueamento, durante décadas, manteve-se intacto o padrão de relações raciais brasileiro, não sendo posto em prática nenhum tipo de política que pudesse efetivamente corrigir as desigualdades raciais. De acordo com Bernardino (2002), a maneira brasileira de encarar o problema racial define como racista aquele que separa, evitando-se reconhecer o tratamento diferenciado de brasileiros em decorrência da raça, mesmo se este reconhecimento pudesse significar uma oportunidade para a correção de desigualdades. Nesse sentido, Lewgoy (2005) compara políticas afirmativas raciais à experiência da África do Sul, com o apartheid, e da Alemanha, com o nazismo, para defender que o Estado moderno deve ser laico e impessoal em sua valorização dos cidadãos, e desrracializado em suas políticas públicas. Por outro lado, Moehlecke (2004) ressalta que as políticas de ação afirmativa tencionam não apenas os marcos da tradição liberal universalista e sua noção de igualdade e mérito, mas também a noção brasileira de povo mestiço convivendo sob uma harmonia racial. Para Alves e Galeão-Silva (2004, p. 22), "a ideia de 
ação afirmativa baseia-se na compreensão de que os fenômenos sociais não são naturais, mas resultado das diversas interações sociais; assim, haveria necessidade de intervenção política na reversão do quadro de desigualdade que se observa em uma dada sociedade".

A discussão sobre como combater o racismo no Brasil é antiga e as primeiras discussões sobre ações afirmativas no país ocorrem desde pelo menos 1995, quando o país solicitou a cooperação técnica da Organização Internacional do Trabalho (OIT) no sentido de efetivar e implementar políticas que promovessem a igualdade de oportunidades e de tratamento no emprego e na ocupação (ALVES; GALEÃO-SILVA, 2004), após o país ter sido denunciado pelo descumprimento de sua Convenção 111, de 1968, que proíbe todas as formas de discriminação (racial, de gênero, religiosa etc.) no mercado de trabalho (ALBERTI; PEREIRA, 2007). Nesse sentido, Teixeira (2018), ao analisar dados históricos sobre as desigualdades raciais, bem como diversos estudos já realizados sobre o tema, destaca a persistência dessas desigualdades ao longo das décadas e reforça que estamos lidando com uma questão que está no nível da estrutura social e, assim, iniciativas voltadas à redução dessas desigualdades levam tempo para refletir sobre uma mudança estrutural.

Um dos principais obstáculos à democracia é a distância entre a lei e a sua efetividade. No Brasil, apesar de existir liberdade e igualdade formais, há uma tradição discriminadora, hierárquica e preconceituosa, comprometendo a efetividade da democracia. Só políticas desiguais para os desiguais são capazes de levar a uma igualdade efetiva. Santos et al. (2008) destacam as desigualdades na esfera da educação, reflexo do processo de formação desigual e injusta do país. Segundo os autores, a expansão contemporânea do acesso ao ensino público na educação básica, começa a demandar a ampliação dos cursos superiores. Neves (2007) destaca que o impacto das novas demandas sobre a educação superior é sentido e equacionado de modo distinto entre os diferentes países, em virtude da história de seus sistemas de ensino, de sua organização, capacidade de reação, de mobilização de recursos e de implantação de políticas pertinentes.

No caso do Brasil, Daflon, Feres Júnior e Campos (2013) apontam para uma predominância da percepção de que as desigualdades de classe são mais relevantes do que as desigualdades raciais entre os articuladores das ações afirmativas para o Ensino Superior no nível local. Conforme Carvalho (2006), os dados sobre o perfil dos estudantes no Ensino Superior revelam que a democratização do ensino é bastante complexa no Brasil, diante da brutal desigualdade de renda entre as famílias e a reduzida parcela do ensino gratuito e de qualidade. Santos et al. 
(2008) apontam a educação formal e de qualidade nos diferentes níveis de ensino como direito formal e substantivo de todos os grupos sociorraciais como forma de amenizar as desigualdades e possibilitar que todos os grupos sociais brasileiros desenvolvam o seu potencial humano. Nesse sentido, Pinto (2005) ressalta que a eficácia social da política de cotas não pode ser medida apenas em termos da entrada de um certo número de pessoas "negras" ou "carentes" na universidade, mas também nas possibilidades criadas para que essas pessoas possam se manter na universidade e criar trajetórias acadêmicas e profissionais de sucesso.

No início dos anos 2000, começaram a ser implantadas as primeiras políticas afirmativas no Ensino Superior brasileiro. Assim, algumas instituições de Ensino Superior públicas começaram a implantar as primeiras políticas de cotas raciais e sociais em seus vestibulares. Moehlecke (2004) afirma que as políticas de ação afirmativa implantadas nas universidades brasileiras surgiram articuladas com movimentos sociais que exigiam maior igualdade e mecanismos mais equitativos no acesso a bens e serviços. Daflon, Feres Júnior e Campos (2013) citam os casos da Universidade do Estado do Rio de Janeiro (UERJ) e da Universidade Estadual do Norte Fluminense Darcy Ribeiro (UENF), que chamaram a atenção quando reservaram $40 \%$ das vagas para a população negra e parda, de acordo com os termos da Lei Estadual no 3.708, de 9 de novembro de 2001, apesar de, desde 2000, vigorar a Lei Estadual $n^{\circ} 3.524$, que havia instituído 50\% das vagas nas universidades estaduais para alunos de escolas públicas. Além disso, em 2005, o Governo Federal implantou nacionalmente o Programa Universidade para Todos (PROUNI), dirigido aos estudantes de renda mais baixa e que tem como finalidade a concessão de bolsas de estudo integrais e parciais em instituições privadas de educação superior, reservando uma parte das vagas a pretos, pardos e índios. Cabe observar que a expansão do acesso ao Ensino Superior ganhou relevância nos últimos anos. Nesse sentido, o Governo Federal implantou, além do PROUNI, diversos programas de estímulo à expansão do acesso ao nível de ensino, como o Fundo de Financiamento Estudantil (Fies), o Programa de Apoio a Planos de Reestruturação e Expansão das Universidades Federais (Reuni), e o Sistema de Seleção Unificada (SISU).

O papel do Estado no financiamento do sistema de Educação Superior tem crescido, mas ainda não resolveu os problemas mais importantes no sistema de Educação Superior brasileiro: acesso, permanência e qualidade. Moehlecke (2004) reforça essa ideia, argumentando que o sistema de Ensino Superior brasileiro, nos debates sobre sua reforma e expansão, tem diante de si o desafio de encontrar soluções que respondam à questão das desigualdades raciais no acesso às suas instituições e na permanência nelas. A expansão do Ensino Superior público (englobando graduação, pós-graduação, pesquisa e extensão), 
aliada a políticas afirmativas que garantam o acesso aos grupos mais excluídos, bem como a melhoria do ensino público em todos os níveis, é que vai permitir a diminuição das desiguais sociais e maior equidade entre todos os grupos populacionais. Nesse sentido, para Guarnieri e Melo-Silva (2007), as reflexões sobre a elitização das universidades públicas brasileiras vêm sendo retomadas de modo a relacionar as consequências da escassa representatividade de negros e povos indígenas na universidade com a incipiente mobilização do interesse acadêmico para produção científica consistente que vise a melhorar a situação de grupos sociais em situação de desvantagem.

Campos, Feres Júnior e Daflon (2014) ressaltam que apesar de a universidade ser, por sua natureza, diferente da Educação Básica ou de outros direitos sociais, necessariamente franqueados a todos os cidadãos, e, consequentemente, precisar estabelecer critérios e normas de seleção que visem a garantir um corpo discente qualificado, isso não justifica sua monopolização por uma elite econômica e/ou racial. Assim, os autores defendem a universidade como um espaço que, se não tem, necessariamente, que acolher a todos, deve ser ao menos uma opção à qual todos têm o direito de aspirar. Daflon, Feres Júnior e Campos (2013) reforçam que, até a aprovação da Lei ${ }^{\circ} 12.711$, em 29 de agosto de 2012, a ação afirmativa se disseminou pelo país de forma heterogênea, a partir de iniciativas locais, como leis estaduais e deliberações de conselhos universitários. Nessa perspectiva, a implementação de uma lei nacional, que impacte o país como um todo, pode contribuir para redução das desigualdades e para o combate ao racismo.

\section{Perspectiva de acesso ao Ensino Superior}

Santos et al. (2008) defendem que a inserção diferenciada de grupos excluídos no Ensino Superior contribui para amenizar a desigualdade no acesso à educação, bem como possibilita a convivência entre estudantes de classes sociais e grupos raciais diferentes, colaborando para a redução da discriminação, com a geração de novas referências para a sociedade. Nesse sentido, torna-se importante notar que, em um primeiro momento, pode haver uma rejeição desse novo padrão, sob o argumento de que essa inserção diferenciada se consubstancia privilégio. No entanto, ao passo que a participação desses grupos excluídos se torne rotina, o questionamento perde significado. Além disso, cabe destacar que a criação de novos parâmetros, onde não predominem apenas brancos e ricos, estimula a busca de novos horizontes para aqueles que hoje não possuem referencial. De acordo com Gomes e Moraes "o ingresso de um contingente maior da população na Educação Superior fortalece os movimentos para alterar os mecanismos de acesso e seleção, face a superação da concepção de Educação Superior como privilégio de classe, que cede lugar à ancoragem social de educação como 
direito". Se brancos têm pais com mais anos de estudo, maior renda, acesso à educação de mais qualidade, maior acesso à cultura, livros e bibliotecas, como é possível argumentar que igualdade de condições é uma prova de vestibular cego às diferenças? $\mathrm{O}$ vestibular tradicional mede a qualidade do sistema escolar e das condições sociais, e não o mérito dos estudantes.

Daflon, Feres Júnior e Campos (2013) destacam que, ao contrário do que postulam aqueles que defendem políticas estritamente sociais, a sobreposição entre negritude e pobreza não necessariamente torna a ação afirmativa baseada exclusivamente na classe um mecanismo eficaz de inclusão de grupos etnicorraciais discriminados. Segundo os autores, quando as ações afirmativas se baseiam apenas no critério da renda familiar, o número de potenciais beneficiários provenientes dos grupos etnicorraciais discriminados cai substantivamente e se eleva o percentual de potenciais beneficiários de grupos que não sofrem discriminação. Já quando a admissão se baseia em critérios etnicorraciais, essas políticas realmente beneficiam membros de grupos discriminados e o objetivo da política afirmativa é atingido de forma mais eficaz.

Fica claro que a universalização do acesso ao Ensino Superior e a democratização do ingresso no ensino público ainda têm um longo caminho. Campos, Feres Júnior e Daflon (2014) argumentam que o vestibular legitimava-se a partir da visão de que ele consiste em um tipo de exame que afere de forma precisa e isenta o "mérito", os conhecimentos acumulados e as habilidades cognitivas, dos candidatos, sem interferência de fatores como sua origem, cor, sexo, classe etc. No entanto, segundo o autor, há evidências sólidas de que o vestibular, em vez de selecionar os melhores alunos, opera como um instrumento de reprodução de hierarquias sociais e raciais no Brasil, já que o capital econômico desempenha um papel decisivo no desempenho dos candidatos, uma vez que ele chancela a capacidade de investimento da família na Educação Básica do estudante. No Brasil, o sistema educacional foi concebido e expandido pelo grupo dominante branco e de elite, que utilizou o conceito de mérito para distribuir ou restringir recompensas educacionais, como se o "mérito" consistisse em aferição de empenho e performance dos indivíduos neutra e cega à cor e classe. Cabe destacar também que a expansão e a democratização do acesso ao Ensino Superior têm impacto não apenas na estrutura produtiva do país, mas no próprio desenvolvimento do setor educacional como um todo, da Educação Básica à qualificação profissional.

Por outro lado, vale salientar a necessidade de constante avaliação e reavaliação das políticas públicas, de modo a identificar e corrigir problemas, bem como fortalecer pontos fortes, já que a multiplicação de políticas afirmativas raciais 
no Ensino Superior deve se traduzir em ampliação do acesso e permanência de estudantes negros, e suas consequências para a posição dessas pessoas na sociedade.

\section{Conclusão}

O mito da democracia racial brasileira já não pode ser sustentado quando tantos dados e pesquisas mostram a exclusão do negro nos níveis mais altos de ensino, nos postos mais altos das organizações, ou mesmo sua predominância no sistema penitenciário do país. As relações raciais no Brasil são, sim, discriminatórias e a negação do racismo apenas perpetua as injustiças sociais em relação aos negros no país. Daflon, Feres Júnior e Campos (2013) destacam que os alunos egressos de escola pública são os maiores beneficiários da onda de políticas de ação afirmativa que atingiu a universidade brasileira, a partir de meados de 2002, seguidos de longe pelos pretos, pardos e indígenas. Nesse sentido, os autores argumentam que a preferência pelas ações afirmativas sociais é possivelmente "a expressão de certa resistência de alguns setores da sociedade brasileira em admitir a modalidade das ações afirmativas raciais, considerando tratar-se de uma nação que, por muito tempo, teve como um dos seus pilares identitários a ideia de 'democracia racial"' (p. 310).

Nesse sentido, Alves e Galeão-Silva (2004) apontam a ambiguidade do discurso gerencial sobre a negação do racismo, em que se afirma que não há preconceito contra negros, mas uma falta de negros qualificados para ocupações valorizadas. Como não haveria preconceito de raça no Brasil, o atraso social do negro decorreria exclusivamente da escravidão, e não do racismo. Essa ocultação do racismo dificulta a implementação de políticas públicas de inclusão por meio do combate ao preconceito racial. Enquanto o brasileiro continuar a definir como racistas os que reconhecem a questão racial como primeiro passo para o combate à discriminação, continuará a negar uma oportunidade para a correção de desigualdades. Nesse sentido, Pinto (2005) destaca as políticas de ação afirmativa, tais como foram concretizadas na criação de cotas na universidade, se constituem, simultaneamente, em canais de acesso a bens culturais e econômicos, como o ensino universitário, para grupos socialmente desfavorecidos e em uma arena de debates, reflexão e ação sobre as próprias categorias raciais, que demarcam a sua inserção e posição na sociedade brasileira.

Moehlecke (2004) ressalta que as políticas de ação afirmativa tratam uma relação complexa de igualdade, que tenciona a tradição moderna baseada nos direitos individuais, ao propor uma redefinição da igualdade de oportunidades liberal, introduzir a utilização de particularidades grupais e ao dar uma ênfase positiva à construção de identidades raciais. Para a efetivação de políticas efetivas de combate 
à discriminação racial, torna-se indispensável o despertar da consciência racial, a consciência individual dos negros em relação à sua negritude, a valorização do negro e o reconhecimento, não só por parte de negros, mas de toda a sociedade, da existência e da profundidade do racismo no Brasil. A questão racial precisa ser claramente nomeada para que a discriminação e o preconceito possam ser plenamente combatidos. O princípio da igualdade deve ser aplicado pelo poder público, levando em conta a necessidade de tratar, desigualmente, os desiguais.

A educação demonstra-se fundamental para a diminuição das desigualdades sociais, econômicas e regionais, indispensáveis para um verdadeiro Estado de direito democrático social. Nesse sentido, as políticas afirmativas adquirem relevância, tendo em vista a ideia de igualdade de oportunidades e de sua respectiva concepção de mérito, não se mostram suficientes para a redução da desigualdade. Nesse sentido, o estudo das políticas públicas é, fundamentalmente, importante na área de Educação, tendo em vista a sua intrínseca relação com as atividades fundamentais do Estado, assim como a reconhecida desigualdade na oferta de ensino.

Assim, são imprescindíveis estudos que analisem as políticas afirmativas raciais implantadas no Ensino Superior brasileiro, de modo a identificar se as formatações dessas políticas realmente ajudam a ampliar o acesso ao Ensino Superior às camadas mais excluídas da população; se essas ações realmente permitem a inserção da população negra no Ensino Superior público; se as cotas contribuem para a permanência dos estudantes beneficiados até a conclusão do curso; e, finalmente, se as políticas afirmativas alteram a percepção de acesso ao Ensino Superior, levando os jovens que, antes nem completavam o Ensino Básico, a ter outra perspectiva de futuro na medida em que podem ter acesso ao Ensino Superior, e, assim, à melhor qualificação profissional, melhores empregos e melhor qualidade de vida. Eis aqui uma agenda de pesquisa imprescindível para desmontar, peremptoriamente, o mito da democracia racial. 


\section{How the access to education dispels the myth of racial democracy}

\section{Abstract}

This essay aims to show how education, particularly access to Higher Education, is an excellent indicator to dismantle the myth of racial democracy constituted in the Brazilian imaginary. Thus, the text is divided into three parts and conclusion. First, arguments about the idea of racial democracy are presented and discussed. Then, affirmative action policies are analyzed. Next, the possibilities of access to higher education by blacks are analyzed. In the conclusion, the article discusses the importance of policies to combat racial inequalities, highlighting a research agenda that would enable to understand to what extent affirmative policies would be able to change the Brazilian racial frame.

Keywords: Higher education. Access. Affirmative action policies. Inequality.

\section{Cómo el acceso a la educación desmonta el mito de la democracia racial}

\section{Resumen}

Este ensayo pretende mostrar cómo la educación, particularmente el acceso a la Enseñanza Superior, es un excelente indicador para desmontar el mito de la democracia racial constituido en el imaginario brasileño. Así, el texto se divide en tres partes y conclusión. En primer lugar, se presentan y debaten los argumentos relativos a la idea de democracia racial. A continuación, se analizan las políticas de acción afirmativa. Después, se analizan las posibilidades de acceso de los negros a la Enseñanza Superior. En la conclusión, el artículo discute la importancia de políticas para el combate a las desigualdades raciales, destacando una agenda de investigación que posibilitaría entender en qué medida las políticas afirmativas serían capaces de cambiar el cuadro racial brasileño.

Palabras clave: Educación superior. Acceso. Politicas afirmativas. Desigualdad. 


\section{Referências}

ALBERTI, V.; PEREIRA, A. A. Movimento negro e "democracia racial" no Brasil: entrevistas com lideranças do movimento negro. Rio de Janeiro, RJ: Centro de Pesquisa e Documentação de História Contemporânea do Brasil, 2005.

. As articulações entre movimento negro e estado: estratégias e experiências contemporâneas. In: GOMES, A. C. (Org.). Direitos e cidadania: memória, política e cultura. Rio de Janeiro, RJ: Fundação Getúlio Vargas, 2007. p. 93-113

ALVES, M. A.; GALEÃO-SILVA, L. G. A crítica da gestão da diversidade nas organizações. Revista de Administração de Empresas, São Paulo, v. 44, n. 3, p. 20-9, 2004. https://doi.org/10.1590/S0034-75902004000300003

ARAÚJO, J. Z. O negro na dramaturgia, um caso exemplar da decadência do mito da democracia racial brasileira. Estudos Feministas, Florianópolis, v. 3, n. 16, p. 979-85, set./dez. 2008. https://doi.org/10.1590/S0104-026X2008000300016

AVRITZER, L.; GOMES, L. C. B. Política de reconhecimento, raça e democracia no Brasil. Dados: Revista de Ciências Sociais, Rio de Janeiro, v. 56, n. 1, p. 39-68, jan./mar. 2013. https://doi.org/10.1590/S0011-52582013000100003

BALTAZAR, S. M. A liberalização do serviço de ensino superior no Brasil: da desestatização ao marco regulatório. Raízes Jurídicas, Curitiba, v. 3, n. 2, p. 435-75, jul./dez. 2007.

BAYMA, F. Reflexões sobre a constitucionalidade das cotas raciais em universidades públicas no Brasil: referências internacionais e os desafios pós-julgamento das cotas. Ensaio: Avaliação e Políticas Públicas em Educação, Rio de Janeiro, v. 20, n. 75, p. 325-46, abr./jun. 2012. https://doi.org/10.1590/S0104-40362012000200006

BERNARDINO, J. Ação afirmativa e a rediscussão do mito da democracia racial no Brasil. Estudos Afro-Asiáticos, Rio de Janeiro, v. 24, n. 2, p. 247-73, 2002. https://doi.org/10.1590/S0101-546X2002000200002

CAMPOS, L. A.; FERES JÚNIOR, J.; DAFLON, V. T. O desempenho dos cotistas no ENEM: comparando as notas de corte do SISU. Rio de Janeiro, RJ: Instituto de Estudos Sociais e Políticos, 2014. (Textos para discussão GEMAA, n. 4). 
CARVALHO, C. H. A. O PROUNI no governo Lula e o jogo político em torno do acesso ao ensino superior. Educação e Sociedade, Campinas, v. 27, n. 96, p. 979-1000, out. 2006. https://doi.org/10.1590/S0101-73302006000300016

DAFLON, V. T.; FERES JÚNIOR, J.; CAMPOS, L. A. Ações afirmativas raciais no ensino superior público brasileiro: um panorama analítico. Cadernos de Pesquisa, São Paulo, v. 43, n. 148, p. 302-27, jan./abr. 2013. https://doi.org/10.1590/S0100-15742013000100015

GOMES, A. M.; MORAES, K. N. A Expansão da educação superior no Brasil contemporâneo: questões para o debate. Rio de Janeiro, RJ: Associação Nacional de Pós-Graduação e Pesquisa em Educação, 2009. (Grupo de trabalho ANPED, 11). Disponível em: < http://www.anped11.UERJ.br/32/gt115848--int.pdf $>$. Acesso em: 20 jan. 2014.

GUARNIERI, F. V.; MELO-SILVA, L. L. Ações afirmativas na educação superior: rumos da discussão nos últimos cinco anos. Psicologia \& Sociedade, Porto Alegre, v. 19, n. 2, p. 70-8, maio/ago. 2007. https://doi.org/10.1590/S0102-71822007000200010

GUIMARÃES, A. S. A. Racismo e antirracismo no Brasil. Novos Estudos, n. 43, p. 26-44, nov. 1995.

INSTITUTO BRASILEIRO DE GEOGRAFIA e ESTATÍSTICA - IBGE. Características étnicorraciais da população: um estudo das categorias de classificação de cor ou raça. Rio de Janeiro, RJ, 2011. RJ, 2016.

Pesquisa nacional por amostra de domicílios 2015. Rio de Janeiro, . Pesquisa nacional por amostra de domicílios 2013. Rio de Janeiro, RJ, 2015.

INSTITUTO DE PESQUISA ECONÔMICA APLICADA - IPEA. Retrato das desigualdades de gênero e raça - 1995 a 2014. Brasília, DF, 2015. Disponível em: $<$ http://www.IPEA.gov.br/retrato/indicadores.html $>$. Acesso em: 16 jan. 2015.

LEWGOY, B. Cotas raciais na UNB: as lições de um equívoco. Horizontes Antropológicos, Porto Alegre, v. 11, n. 23, p. 218-21, jan./jun. 2005. https://doi.org/10.1590/S0104-71832005000100013 
MOEHLECKE, S. Ação afirmativa no ensino superior: entre a excelência e a justiça racial. Educação e Sociedade, Campinas, v. 25, n. 88, p. 757-76, out. 2004. https://doi.org/10.1590/S0101-73302004000300006

NEVES, C. E. B. Desafios da educação superior. Sociologias, Porto Alegre, v. 9, n. 17, p. 14-21, jan./jun. 2007.

OLIVEIRA FILHO, P. A mobilização do discurso da democracia racial no combate às cotas para afrodescendentes. Estudos de Psicologia, Campinas, v. 26, n. 4, p. 429-36, out./dez. 2009. https://doi.org/10.1590/S0103-166X2009000400003

PEREIRA, A. A. O "Atlântico negro" e a constituição do movimento negro contemporâneo no Brasil. Perseu: História, Memória e Política, São Paulo, n. 1, p. 235-63, dez. 2007.

PERONI, V. M. V.; OLIVEIRA, R. T. C.; FERNANDES, M. D. E. Estado e terceiro setor: as novas regulações entre o público e o privado na gestão da educação básica brasileira. Educação \& Sociedade, Campinas, v. 30, n. 108, p. 761-78, out. 2009. https://doi.org/10.1590/S0101-73302009000300007

PINTO, P. G. H. R. Ação afirmativa, fronteiras raciais e identidades acadêmicas: uma etnografia das cotas para negros na UERJ. In: CONFERÊNCIA INTERNACIONAL DA REDE DE ESTUDOS SOBRE AÇÃO AFIRMATIVA, 1, 2005, Rio de Janeiro. Anais... Rio de Janeiro, RJ: Universidade Cândido Mendes. Disponível em: <http://aasn.iuperj.br/Articles/ Paulo_Gabriel_Hilu.pdf $>$. Acesso em: 16 fev. 2015.

SANTOS, S. A. et al. Ações afirmativas: polêmicas e possibilidades sobre igualdade racial e o papel do Estado. Revista Estudos Feministas, Florianópolis, v. 16, n. 3, p. 913-29, set./dez. 2008. https://doi.org/10.1590/S0104-026X2008000300012

SENADO FEDERAL. Constituição da República Federativa do Brasil de 1988. Brasília, DF, 1988.

TEIXEIRA, M. P. Democratizing the access to college education: brazilian race/color classification in affirmative action's debate. Ensaio: Avaliação e Políticas Públicas em Educação, Rio de Janeiro, v. 26, n. 100, p. 595-618, jul./set. 2018. https://doi.org/10.1590/s0104-40362018002601768 


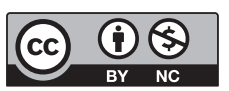

\section{Informações da autora}

Nara Torrecilha Ferreira: Doutora em Administração Pública e Governo pela Fundação Getúlio Vargas e Mestre em Administração pela Universidade de Brasília (UNB). Contato: ntorrecilha@gmail.com

iD http://orcid.org/0000-0002-8064-3916 